\title{
Identificação e perfil antimicrobiano de bactérias isoladas de urina de gestantes atendidas na Irmandade da Santa Casa de Misericórdia de Prudentópolis, Paraná
}

\author{
Identification and antimicrobial profile of bacteria isolated from \\ urine of pregnant women treated in the Irmandade da Santa Casa de \\ Misericórdia de Prudentópolis, Paraná
}

\author{
Tássia Klosowski Pacheco dos Santos ${ }^{1}$; Isabela Thomé Sanches²; Elaine Pittner ${ }^{3}$; \\ Hermes Francisco Sanches ${ }^{4}$
}

\section{Resumo}

As infecções urinárias são as mais comuns durante a gravidez, sendo favorecidas pelas mudanças fisiológicas e anatômicas que ocorrem nas gestantes. Tendo em vista os riscos que tais infecções representam para a mãe e para o feto e as inúmeras falhas em tratamentos com antibióticos, o que muitas vezes resulta na resistência bacteriana a esses medicamentos, o objetivo deste trabalho é identificar os agentes causadores de infecção do trato urinário em gestantes atendidas na Irmandade da Santa Casa de Misericórdia de Prudentópolis, Paraná e investigar a sensibilidade antimicrobiana frente aos antibióticos Ciprofloxacina, Nitrofurantoina, Gentamicina, Norfloxacina, Ampicilina e Oxacilina, a partir de amostras de urina proveniente de gestantes atendidas na Irmandade da Santa Casa de Misericórdia de Prudentópolis, Paraná. Foram analisadas 50 amostras de urina e encontrou-se uma prevalência de $90 \%$ de Escherichia coli e 10\% de Proteus mirabilis. Essas bactérias apresentaram uma maior sensibilidade aos antibióticos Ciprofloxacina, Nitrofurantoína, Norfloxacina e Gentamicina, resultados semelhantes aos obtidos em pesquisas realizadas por outros autores. E. coli continua sendo a bactéria mais isolada em infecções do trato urinário em gestantes, e é importante ressaltar a importância da realização do antibiograma para garantir a eficácia do tratamento.

Palavras-chave: Gravidez. Infecção urinária. Antibiograma.

\begin{abstract}
Urinary infections are the most common ones during pregnancy, being favored by the physiological and anatomical changes that occur in pregnant women. Having in mind the risks that such infections represent to the mothers and their babies, and also the numerous failure in the treatment with antibiotics, which may result in bacterial resistance to these kinds of medicine, the aim of this work is to identify the causing agents of urinary tract infections in pregnant women assisted at the hospital called Irmandade da Santa Casa de Misericórdia in Prudentópolis, Paraná. It also aims at investigating the antimicrobial sensitivity to the following antibiotics: Ciprofloxacin, Nitrofurantoin, Gentamicin,
\end{abstract}

\footnotetext{
${ }^{1}$ Universidade Estadual do Centro-Oeste (UNICENTRO), Paraná, Brasil. E-mail: tassiakps@hotmail.com. ${ }^{2}$ Universidade Estadual do Centro-Oeste (UNICENTRO), Paraná, Brasil. E-mail: isat_sanches@hotmail.com. ${ }^{3}$ Universidade Estadual do Centro-Oeste (UNICENTRO), Paraná, Brasil. E-mail: elainepittner@hotmail.com. ${ }^{4}$ Universidade Estadual do Centro-Oeste (UNICENTRO), Paraná, Brasil. E-mail: hermessanches@hotmail.com.
} 
Norfloxacin, Ampicillin and Oxacillin, with basis on urine samples by pregnant women assisted at the Irmandade da Santa Casa de Misericórdia de Prudentópolis, Paraná. Fifty samples of urine were analyzed and a prevalence of $90 \%$ of Escherichia coli and 10\% of Proteus mirabilis were found. These bacteria presented higher sensitivity to the antibiotics Ciprofloxacin, Nitrofurantoin, Norfloxacin and Gentamicin. Similar results were obtained in research carried out by other authors. E. coli is still the most isolated bacterium in urinary infections in pregnant women. Therefore, it is essential to highlight the importance of an antibiogram to guarantee the efficiency of the treatment.

Keywords: Pregnancy. Urinary infection. Antibiogram

\section{Introdução}

A infecção do trato urinário (ITU) caracteriza-se como a invasão e colonização de bactérias nos rins e nas vias urinárias (GUIDONI; TOPOROVSKI, 2001). É uma patologia muito freqüente que atinge pessoas de todas as idades. No primeiro ano de vida acomete mais crianças do sexo masculino, devido ao maior número de malformações congênitas. A partir deste momento, seguindo por toda a infância, a ITU passa a ser mais freqüente em crianças do sexo feminino, mantendo-se mais comum neste mesmo sexo durante a vida adulta, com maiores índices de infecção no início da atividade sexual, durante a gestação e/ou na menopausa (HEILBERG; SCHOR, 2003).

O agente etiológico mais freqüente na infecção urinária é a Escherichia coli, detectada em cerca de 80 a $90 \%$ das infecções bacterianas agudas não-complicadas das vias urinárias. Nas infecções complicadas, o número de bactérias infectantes e sua diversidade são maiores. Verifica-se frequentemente a presença de E. coli, mas também aparecem outros bastonetes gram-negativos como Proteus, Klebsiella, Enterobacter e Pseudomonas (SATO et al., 2005).

A maioria dos casos de infecção urinária são causados pela Escherichia coli, uma enterobactéria reponsável pelas infecções mais simples até os casos mais complicados, como uma pielonefrite crônica. A patogenicidade dessa bactéria é maior em mulheres devido a sua posição anatômica. A colonização do trato urinário ocorre por um acesso de bactérias intestinais do ânus até o orifício urinário, comprometendo bexiga, ureteres, rins e uretra. Geralmente, infecções deste gênero afetam primeiramente a uretra e, se esta não for tratada, acometem a bexiga e os ureteres, porém, a infecção de maior risco é a pielonefrite (nos rins), podendo evoluir para uma septcemia e até a morte (LOURA; FERNANDES, 2010).

Infecções do trato urinário são as infecções mais comuns durante a gravidez. Elas são classificadas como sintomáticas ou assintomáticas. A bacteriúria assintomática é definida como a presença de bacteriúria significativa sem os sintomas de infecção aguda. Infecções sintomáticas são divididas em infecções do trato inferior (cistite aguda) e infecções do trato superior (pielonefrite aguda). Cistite está relacionada com a invasão da mucosa da bexiga, enquanto a pielonefrite está associada à inflamação do parênquima renal, cálices e pelve (SCHNARR; SMAILL, 2008).

A cistite, quando sintomática, tem como principais sintomas a disúria, urgência miccional, polaciúria, nictúria e dor suprapúbica. A urgência miccional já está comumente presente em gestantes, dificultando ainda mais o diagnóstico de infecção do trato urinário por não correlacionar este sintoma com uma infecção. Já a pielonefrite, que normalmente se inicia como um quadro de cistite, é 
normalmente acompanhada por um quadro de febre (geralmente superior a $38^{\circ} \mathrm{C}$ ), calafrios e dor lombar uni ou bilateral (LOPES; TAVARES, 2005).

A prevalência de bacteriúria assintomática na gravidez é de até $10 \%$, e é observada durante o início da gestação até o terceiro trimestre. 25 a $57 \%$ dessas bacteriúrias não tratadas podem evoluir para infecção sintomática como a pielonefrite. Por isso, a gravidez é a única indicação absoluta de tratamento de bacteriúria assintomática (HEILBERG; SCHOR, 2003).

As mudanças anatômicas e fisiológicas que ocorrem no trato urinário da mulher durante a gestação favorecem o aparecimento de infecções urinárias sintomáticas (DUARTE et al., 2002). Essas alterações incluem: dilatação pélvica e hidroureter, aumento do tamanho renal, modificação da posição da bexiga, aumento da capacidade vesical devido a redução do tônus vesical regulado por hormônio, relaxamento da musculatura lisa da bexiga e ureter progesterona-mediado (HEILBERG; SCHOR, 2003).

A diminuição da capacidade renal de concentrar a urina durante a gravidez reduz a atividade antibacteriana desse fluido, pois excreta menores quantidades de potássio e maiores de glicose e aminoácidos, assim como produtos de degradação hormonal, o que propicia um meio ideal para a proliferação bacteriana. Nesse período observase que a urina da grávida fica mais alcalina e isso também favorece o crescimento das bactérias presentes no trato urinário. Além disso, o hiperestrogenismo gestacional contribui para a adesão de algumas cepas de Escherichia coli, portadoras de adesina tipo I, às células uroepiteliais (DUARTE et al., 2008).

ITU durante a gestação se associa a um maior índice de parto prematuro, ruptura prematura de membrana amniótica, restrição de crescimento intra-útero, retardo mental e mortalidade perinatal (SALCEDO et al., 2010). Já as complicações maternas são secundárias ao dano tecidual causado pelas endotoxinas bacterianas, ocorrendo principalmente nos casos de pielonefrite. A presença de bacteremia é demonstrada em 15 a 20\% das gestantes com pielonefrite grave. Pode ocorrer também insuficiência respiratória decorrente do aumento da permeabilidade da membrana do alvéolo-capilar, resultando em edema pulmonar (DUARTE et al., 2008).

Novamente o uropatógeno mais comum é a Escherichia coli, que é responsável por cerca de $80 \%$ dos casos de ITU em gestantes. Outras bactérias gram-negativas contribuem para a maioria dos casos restantes, tais como Klebsiella pneumoniae, Proteus mirabilis e bactérias do gênero Enterobacter. Algumas bactérias gram-positivas também podem causar ITU, embora com uma prevalência baixa, destacando-se Staphylococcus saprophyticus e Streptococcus agalactiae (DUARTE et al., 2008).

A realização de um antibiograma com antibióticos apropriados possibilita uma melhor adequação dos tratamentos, prevenindo o fracasso terapêutico utilizando antimicrobianos eficazes contra os patógenos da amostra (MORENO, 2002).

Os antibióticos, com um amplo espectro de ação para as bactérias de infecções como cistite, uretrite ou pielonefrite, mais usados são gentamicina, ciprofloxacina, norfloxacina (quinolonas), nitrofurantoína, os aminoglicosídeos e cefalosporinas de segunda e terceira geração (KOCH et al., 2008; LO et al., 2010; PIRES et al., 2007). As bactérias apresentaram maior resistência a ampicilina, porém esse antibiótico ainda tem ação antimicrobiana e deve ser usado em casos que as bactérias são mais resistentes aos outros antibióticos ou quando o paciente possui sensibilidade aos outros medicamentos (LO et al., 2010; PIRES et al., 2007). A oxacilina é um antibiótico $\beta$-lactâmico isonazolil penicilina, e é utilizada em ITU, porém quando as infecções são causadas por bactérias gram-positivas, como por exemplo, Staphylococcus aureus (HEILBERG; SCHOR, 2003; QUEIROZ; REIS, 2005). A oxacilina, antibiótico nomeado 
penicilina resistente, é muito utilizada para esses microrganismos produtores de penicilase, pois representou avanço significativo na terapia antiestafilocócica (HEILBERG; SCHOR, 2003; SILVA, 2007).

As infecções urinárias estão entre as principais complicações do pré-natal, e possuem um significado estatístico como causa de parto prematuro, além dos riscos já citados acima (ARAÚJO et al., 1996; NASCIMENTO, 2001). Com isso, o objetivo desse trabalho foi selecionar colônias e traçar perfil de sensibilidade antimicrobiana de bactérias encontradas em mulheres grávidas, pacientes do Hospital da Santa Casa de Prudentópolis-PR.

\section{Material e Métodos}

\section{Amostras}

Foram analisadas 50 amostras coletadas no período de junho de 2010 a junho de 2011. As amostras analisadas foram provenientes da Irmandade da Santa Casa de Misericórdia do município de Prudentópolis, Paraná. Elas foram obtidas a partir da cultura da urina de gestantes, as quais foram orientadas a coletar a urina de jato médio, em frascos estéreis e encaminhar imediatamente ao laboratório. As amostras foram analisadas dentro de 2 horas após a coleta. Após ser feito o exame de urina do tipo I e a análise microscópica do sedimento, os quais indicaram presença de bacteriúria, as amostras biológicas foram semeadas em ágar Cled e ágar MacConkey pela técnica quantitativa, utilizando alça calibrada de $10 \mu \mathrm{L}$, e foram selecionadas as culturas que apresentaram mais de $10^{5} \mathrm{UFC} / \mathrm{mL}$ (HEILBERG; SCHOR, 2003).

\section{Identificação das bactérias}

Foi realizada a coloração de Gram das amostras analisadas, para a classificação inicial como gram- positiva ou gram-negativa. De acordo com o resultado da coloração, prosseguiram-se os testes de identificação. As bactérias gram-negativas foram submetidas ao teste das tiras de oxidase, que as classificam como enterobactérias (oxidase negativa) ou bactérias não-fermentadoras (oxidase positiva).

As oxidases negativas foram semeadas no kit para enterobactérias, composto pelos seguintes meios: meio EPM, caldo lisina, meio de MIO, meio de citrato de Simmons, meio de Rhamnose (NEWPROV, 2011).

Os resultados das provas foram agrupados de três em três e a cada um foi atribuído um valor de acordo com o Manual de Identificação de Enterobactérias do kit utilizado, resultando em uma sequência de quatro números, os quais foram analisados nesse mesmo manual, que fornece o resultado final com percentual de probabilidade.

\section{Antibiograma}

O Antibiograma foi realizado pelo método de Kirby e Bauer. Foi preparado Agar Müller Hinton, seguindo as orientações do fabricante. $\mathrm{O}$ inóculo foi preparado a fim de se obter uma suspensão 0,5 da escala de McFarlland, ou seja, 1,5 x 10 UFC/ $\mathrm{ml}$. O controle da escala foi feio visualmente através de comparação visual com o padrão de turvação correspondente ao tubo 0,5 de McFarlland (LABORCLIN, 2011).

Após a obtenção do inoculo ideal, um swab estéril foi introduzido na suspensão de bactérias, para a retirada do excesso de amostra do mesmo foi aplicado uma leve compressão do swab nas paredes do tubo de vidro antes da semeadura. No Agar Müller Hinton, previamente preparado e autoclavado, foi semeado o inóculo de bactérias uniformemente por rotações de 60 graus e nas bordas, não deixando espaços entre as estrias (LABORCLIN, 2011).

Os discos de difusão individuais de cada antibiótico foram previamente selecionados a partir dos trabalhos "Abordagem diagnóstica e terapêutica 
na infecção do trato urinário - ITU" de HEILBERG, I.P. et al, 2003 e o trabalho "Susceptibilidade antimicrobiana de bactérias isoladas de infecções do trato urinário de pacientes atendidos no Hospital Universitário Bettina Ferro de Souza - Belém/PA" de VIEIRA, J.M.S. et al, os quais utilizaram um ou mais antibióticos escolhidos para o presente estudo,

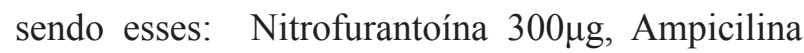
$10 \mu \mathrm{g}$, Ciprofloxacina $5 \mu \mathrm{g}$, Norfloxacina 10 $\mu \mathrm{g}$, Gentamicina $10 \mu \mathrm{g}$ e Oxacilina $1 \mu \mathrm{g}$ (BAIL; SANCHES; ESMERINO, 2006; DIAS NETO et al., 2003; DUARTE et al., 2002; HEILBERG; SCHOR, 2003).

Ao Agar Müller Hinton, que continha as bactérias já semeadas, os discos selecionados foram fixados com auxílio de uma pinça estéril a uma distância mínima de $24 \mathrm{~mm}$ de centro a centro entre eles. Assim que os discos entrarem em contato com o meio de cultura, não devem mais ser retirados. Em caso de derrubarmos o disco em lugar indevido, o antibiograma deve ser descartado e refeito (CEFAR, 2011).

As placas foram levadas para estufa microbiológica com temperatura de aproximadamente $37^{\circ} \mathrm{C}$, e ficaram incubadas por 24 horas (CEFAR, 2011).

Após o período de 24 horas, observou-se o crescimento bacteriano e existência ou não dos halos formados pela difusão circular e uniforme dos discos de antibióticos. Nos casos em que apareceram esses halos, eles foram medidos com régua Standards (NCCLS) e devidamente documentados (CEFAR, 2011).

Para a interpretação dos resultados foi utilizada a tabela CLSI (CLSI, 2011). Após a medição dos halos a definições classificação foi a seguinte: Sensível (sugere que a cepa pode ser tratada com as doses usualmente recomendadas), Intermediária (ocorre quando o diâmetro do halo se encontra próximo ao do resistente) e Resistente (ocorre quando os microrganismos não são inibidos pelas concentrações usuais de antimicrobianos) (SILVA, 2007).

\section{Resultados e Discussão}

Foram analisadas, no período de junho de 2010 a junho de 2011, 50 culturas de urina de gestantes provenientes da Irmandade da Santa Casa de Misericórdia do município de Prudentópolis, Paraná. Das bactérias analisadas, 100\% pertenciam às gram-negativas e faziam parte da família das Enterobactérias, estando de acordo com os dados da literatura que afirmam a prevalência dessa família nas infecções urinárias. (BLATT; MIRANDA, 2005; DACHI, 2000; LOPES; TAVARES, 2005; VIEIRA et al., 2007).

Observou-se a presença de apenas duas bactérias: Escherichia coli, com 90\% de prevalência, e Proteus mirabilis, com 10\%. Jacociunas e Picoli encontraram resultado semelhante sobre infecção urinária em gestantes em artigo publicado em 2007 (Figura 1), pois obtiveram uma porcentagem de $76 \%$ para E. coli e $6 \%$ para $P$. mirabilis. No entanto, nessa pesquisa também foram encontrados Enterococcus sp., Klebsiella sp. e S. saprophyticus, todos com 6\% de prevalência (JACOCIUNAS; PICOLI, 2007).

Assim como o resultado da presente pesquisa, em estudo realizado em 2010 sobre a prevalência de agentes etiológicos causadores de infecção urinária em menores de 15 anos, Lo etal. também encontraram uma predominância de E. coli com $69 \%$, além de $19 \%$ de P. mirabilis. Entretanto, encontraram-se outros agentes em menores porcentagens, como Klebsiella pneumoniae, com 2,8\% (Figura 1) (LO et al., 2010). Resultados similares foram encontrados por Koch et al. (2008) em pesquisa feita com uroculturas positivas do Hospital Universitário da Fundação Universidade Federal do Rio Grande (FURG) no período de janeiro de 2000 a dezembro de 2004, que obteve como resultado E. coli, $P$. mirabilis e Klebsiella $s p$ como as três bactérias mais frequentemente identificadas, com 66,2\%, 8,4\% e $5,6 \%$ respectivamente (Figura 1$)(\mathrm{KOCH}$ et al., 2008).

Em levantamento das uroculturas positivas do Hospital Universitário de Brasília no período de 
2001 a 2005, Pires et al. (2007) encontraram uma predominância de E. coli, com $62,4 \%$, seguida por Klebsiella pneumoniae (6,8\%), Proteus mirabilis (4,7\%), Pseudomonas aeruginosa (2,9\%), Enterobacter aerogenes (2,5\%), Proteus vulgaris $(2,2 \%)$, Staphylococcus saprophyticus (2\%) e outros microrganismos em menores porcentagens (PIRES et al., 2007).

Pode-se observar que em todos os estudos citados, bem como na própria pesquisa realizada, houve uma prevalência de E. coli muito maior que dos outros microrganismos (Figura 1). Isso pode ser explicado pela presença de adesinas nestas bactérias, o que permite a adesão e invasão bacteriana nas células do trato urinário. $90 \%$ das E. coli apresentam as fímbrias tipo I, o que é considerado o principal fator de virulência. Essas bactérias também possuem as fímbrias $\mathrm{P}$, as quais se ligam a receptores específicos no tecido do epitélio renal (MOURA; FERNANDES, 2010). Além disso, a proximidade das regiões anal e genitourinária na mulher favorece o acesso das enterobactérias às vias urinárias (SANTOS et al., 2009).

Figura 1 - Comparação dos resultados obtidos no presente trabalho com os obtidos por Jacociunas e Picoli (2007), Lo et al. (2010), Koch et a.l (2008) e Pires et al. (2007).

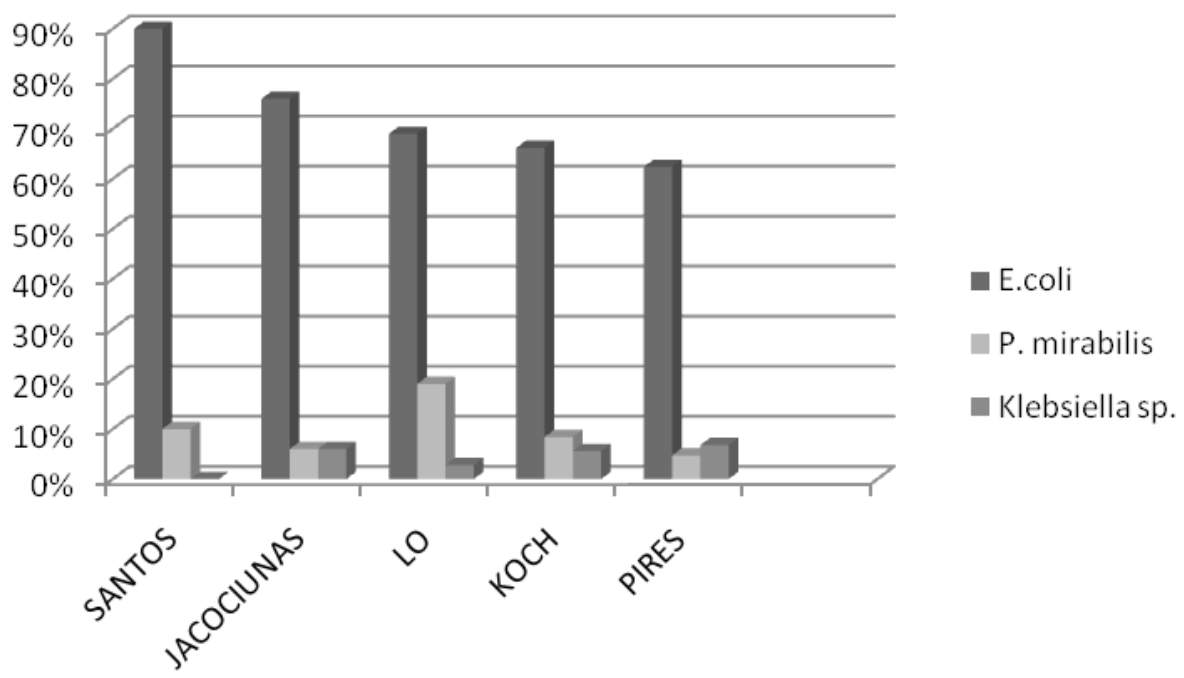

Fonte: Autores.

Os halos de inibição das bactérias frente a antibióticos testados foram medidos com a régua Standards (NCCLS).

A sensibilidade das bactérias a cada antibiótico a partir de seu halo de inibição foi avaliado segundo a tabela CLSI e classificado em sensível, intermediário ou resistente (CLSI, 2011).

Após essa verificação, observou-se que as bactérias Escherichia coli e Proteus mirabilis, apresentaram seguintes porcentagens de sensibilidade e resistência, demonstradas na Tabela 1 e Tabela 2. 
Tabela 1 - Porcentagens de sensibilidade de Escherichia coli frente aos antibióticos testados

\begin{tabular}{lcccccc}
\hline \multirow{2}{*}{ Sensibilidade } & \multicolumn{5}{c}{ Antibióticos } \\
\cline { 2 - 6 } & Nor & Amp & Cip & Nit & Gen & Oxa \\
\hline Sensível & $100 \%$ & $71,1 \%$ & $93,33 \%$ & $88,9 \%$ & $84,44 \%$ & $2,2 \%$ \\
\hline Intermediário & - & $8,9 \%$ & $6,6 \%$ & $6,66 \%$ & $11,11 \%$ & - \\
\hline Resistente & - & $20 \%$ & - & $4,44 \%$ & $4,44 \%$ & $97,8 \%$ \\
\hline
\end{tabular}

Oxa: Oxacilina; Gen: Gentamicina; Nit: Nitrofurantoína; Cip: Ciprofloxacina; Amp: Ampicilina; Nor: Norfloxacina.

Fonte: Autores

Tabela 2 - Porcentagens de sensibilidade de Proteus mirabilis frente aos antibióticos testados

\begin{tabular}{lcccccc}
\hline \multirow{2}{*}{ Sensibilidade } & \multicolumn{5}{c}{ Antibióticos } \\
\cline { 2 - 6 } & Nor & Amp & Cip & Nit & Gen & Oxa \\
\hline \multirow{2}{*}{ Sensível } & $100 \%$ & $80 \%$ & $100 \%$ & $60 \%$ & $60 \%$ & - \\
\hline Intermediário & - & $20 \%$ & - & $20 \%$ & $40 \%$ & - \\
\hline Resistente & - & - & - & $20 \%$ & - & $100 \%$ \\
\hline
\end{tabular}

Oxa: Oxacilina; Gen: Gentamicina; Nit: Nitrofurantoína; Cip: Ciprofloxacina; Amp: Ampicilina; Nor: Norfloxacina.

Fonte: Autores

Em estudo realizado por Lo et al. (2010), a Escherichia coli e Proteus mirabilis apresentaram resultados semelhantes aos mencionados na Tabela 1 e 2, sendo eles, 98,2\% sensíveis à Nitrofurantoína, $96,4 \%$ à Gentamicina, 98,2\% à Ciprofloxacina, $98,2 \%$ a Norfloxacina e 38,7\% à Ampicilina. Já no trabalho de Dias Neto et al. (2003), o estudo realizouse a partir de amostras de urina de 402 pacientes, $37 \%$ das bactérias foram sensíveis à Ampicilina, $88 \%$ à Gentamicina, $73 \%$ à Ciprofloxacina, $77 \%$ à
Nitrofurantoína e $75 \%$ à Norfloxacina.

A Ampicilina, antibiótico antes muito usado para as infecções do trato urinário, apresentou baixo índice de sensibilidade antimicrobiana (71,1\% de Escherichia coli e $80 \%$ de Proteus mirabilis) comparado com outros antibióticos. Encontram-se dados semelhantes na literatura, como, por exemplo, $62 \%$ (PIRES et al., 2007), 60,6\% (DUARTE et al., 2002), e 37\% (DIAS NETO et al., 2003) para 
a Escherichia coli e 100\% para Proteus mirabilis (DUARTE et al., 2002). Esses altos índices de resistência devem-se ao fato de que a antigamente a ampicilina era o antibiótico de escolha para infecções deste gênero. Porém, na atualidade, inviabiliza-se o seu uso para estas situações (DUARTE et al., 2008). Estes números são preocupantes, uma vez que este medicamento é bastante utilizado para infecções urinárias em decorrência do baixo custo relativo (DUARTE et al., 2002).

O antibiótico Norfloxacina, classificado como quinolona, não apresentou resistência nas culturas de urina analisadas (DUARTE et al., 2002). Este alto índice de sensibilidade assemelhamse ao estudo de Lo et al. (2010), em que este antimicrobiano apresentou $98,2 \%$ de sensibilidade para a Escherichia coli e para o Proteus mirabilis e $75 \%$ de sensibilidade na análise, segundo Dias Neto et al. (2003).

As bactérias analisadas, em sua maioria (93,33\% para Escherichia coli e 100\% para Proteus mirabilis), são sensíveis à Ciprofloxacina, antibiótico também classificado como quinolona, e seus altos índices de sensibilidade correspondem a literatura de DIAS NETO, J.A. et al., "Community acquired urinary tract infection: etiology and bacterial susceptibility" de 2003, HEILBERG, I.P.; SCHOR, N. "Abordagem Diagnóstica e Terapêutica na Infecção do Trato Urinário - ITU” de 2003 e também à literaura de LO, D.S. et al. "Infecção urinária em menores de 15 anos: etiologia e perfil de sensibilidade antimicrobiana em hospital geral de pediatria" de 2010 , as quais apresentam índices entre $73 \%$ e $98,2 \%$ para ambas as bactérias (DIAS NETO et al., 2003; HEILBERG; SCHOR, 2003; LO et al., 2010).

As quinolonas são os antibióticos mais indicados para tratamento de infecções não complicadas de ITU e para profilaxia. São drogas de escolha pela facilidade na posologia (administrado duas vezes ao dia), segundo Heilberg e Schor (2003). A Ciprofloxacina e a Norfloxacina apresentaram índices nulos de resistência, análogos a isso o estudo de Lo et al.(2010) mostra que estes antibióticos apresentaram apenas $1,8 \%$ de resistência frente às bactérias que mais atingem o trato urinário.

A Nitrofurantoína é um antibiótico indicado para a profilaxia das infecções urinárias, sendo indicada principalmente para mulheres com ITU recorrente, que apresentam mais do que duas infecções ao ano, ou quando possui fatores que mantém a infecção, como, por exemplo, cálculos (DUARTE et al., 2008; HEILBERG; SCHOR, 2003). Este antibiótico tem alta concentração no trato urinário e induz resistência mínima em organismos Gram negativos (CHEN, 2009). Esta droga apresentou 88,9\% de sensibilidade para E. coli e $60 \%$ para $P$. mirabilis, número semelhante ao encontrado no trabalho "Infecção do Trato Urinário: Comparação Entre o Perfil de Susceptibilidade e a Terapia Empírica com os Antimicrobianos" de Bail, Sanches e Esmerino (2006) que indicou sensibilidade de $89,8 \%$ para ambas bactérias.

A Gentamicina, aminoglicosídeo, tem menor taxa de resistência juntamente com as quinolonas (DUARTE et al., 2008). 84,44\% de E. coli e $60 \%$ de P. mirabilis foram sensíveis a esta droga, número que condiz com a literatura no trabalho Bail, Sanches e Esmerino (2006), o qual apresenta o mesmo índice de $82 \%$ e índice semelhante ao autor Dias Neto et al. (2003), o qual indicou $88 \%$ de sensibilidade para as bactérias encontradas.

A sensibilidade da E. coli, em anos antetiores à Nitrofurantoína manteve-se estável e acima de 90\%, segundo estudo realizado no Hospital das Clínicas de Porto Alegre (1986- 1997) e no Hospital Universitário de Brasília (2001-2005) indicou ótima sensibilidade aos aminoglicosídeos e a Nitrofurantoína (LO et al., 2010).

A Oxacilina é um antimicrobiano penicilina resistente, muito utilizada para microrganismos produtores de Penicilase, tem alta atividade antiestafilocócica, ou seja, se reservam ao tratamento de infecções causadas principalmente por 
Staphylococcus aureus, não sendo eficazes contra bactérias gram-negativas (HEILBERG; SCHOR, 2003; PIRES et al., 2007; QUEIROZ; REIS, 2005; SILVA, 2007; SILVEIRA, 2012). Este fato, explica seu alto índice de resistência às bactérias analisadas (97,8\% para E. coli e $100 \%$ para P. mirabilis), pois tratam-se de enterobactérias.

Como o perfil de resistência dos uropatógenos frente aos agentes antimicrobianos comum está em constante mudança, é de extrema importância a realização do antibiograma no lugar de um tratamento empírico (BAIL; SANCHES; ESMERINO, 2006). No entanto, a escolha de um antibiótico deve levar em conta, além da sensibilidade das bactérias mais prevalentes a ele, outros fatores como: condição do paciente para adquirir a medicação, sua tolerabilidade, a comodidade do esquema posológico, faixa etária, avaliação clínica, sinais de toxemia, histórico de ITU progressa ou uropatias, falha à terapia ambulatorial (DUARTE et al., 2008; LO et al., 2010).

\section{Considerações Finais}

A partir dos resultados obtidos na pesquisa, foi possível correlacionar os dados com aqueles encontrados por outros autores que desenvolveram estudos sobre infecção no trato urinário, sendo comprovada a grande prevalência da enterobactéria Escherichia coli nas ITUs. Esse achado pode ser explicado pelos fatores de virulência apresentados por essa bactéria e pelas condições fisiológicas e anatômicas da gestante. Em todos os trabalhos comparados, assim como na presente pesquisa, também existe a presença de Proteus mirabilis em menores quantidades. Verificou-se também que os antibióticos utilizados, Norfloxacina, Ciprofloxacina e Nitrofurantoína, devem ser de primeira escolha quando comparados à Ampicilina, à Oxacilina e à Gentamicina, pois os primeiros apresentaram índices de sensibilidade maiores, garantindo assim, uma maior eficácia.

Visto a significativa incidência de infecção urinária em gestantes e conhecidos todos os riscos que esta causa para o feto, sabendo-se que a mesma está associada a um maior índice de parto prematuro, restrição de crescimento intra-uterino, retardo mental, além das complicações secundárias relacionadas à mãe (BAHADI et al., 2010), é válido ressaltar a importância de realizar os exames do pré-natal, com o intuito de garantir um diagnóstico precoce de uma possível ITU na gestante, identificando seu agente causador e traçando o perfil de sensibilidade antimicrobiana deste, a fim de obter um tratamento eficaz e seguro.

\section{Referências}

ARAÚJO, D. A. C.; ZIMMERMMANN, J. B.; OLIVEIRA, L. C. N.; ANDRADE, A. T. L. Gestação de alto risco: prevalência de patologias e complicações materno-fetais. Jornal Brasileiro de Ginecologia, Rio de Janeiro, v. 106, n. 8, p. 315-320, ago. 1996.

BAHADI, A.; El KABBAJ, D.; ELFAZAZI, H.; ABBI, R.; HAFIDI, M. R.; HASSANI, M. M.; MOUSSAOUI, R.; ELOUENNASS, M.; DEHAYNI, M.; OUALIM, Z. Urinary tract infection in pregnancy. Saudi Journal of Kidney Diseases and Transplantation, Arábia Saudita, v. 21, n. 2, p. 342-344, 2010.

BAIL, L.; SANCHES, I. C. A.; ESMERINO, L. A. Infecção do trato urinário: comparação entre o perfil de susceptibilidade e a terapia empírica com os antimicrobianos. Revista Brasileira de Análises Clínicas, Rio de Janeiro, v. 38, n. 1, p. 51-56, 2006.

BLATT, J. M.; MIRANDA, M. C. Perfil dos microrganismos causadores de infecções do trato urinário em pacientes internados. Revista Panamericana de Infectología, São Paulo, v.7, n.4, p.10-14, out./dez. 2005.

CEFAR. Antibiograma passo a passo. Disponível em: $<$ http://www.cefar.com.br/download/antibiograma $\% 20$ passo $\% 20 a \% 20 \% 20$ passo.pdf $>$. Acesso em: 21 ago. 2011.

CHEN, K. T. ITU na gravidez: 6 perguntas para orientar o tratamento. $O B G$ Management, v. 1, n. 1, p. 3-9, 2009.

CLSI. Normas de desempenho para testes de sensibilidade antimicrobiana: $15^{\circ}$ suplemento informativo Disponível 
em: $\quad<$ http://www.sbac.org.br/pt/pdfs/biblioteca/clsi OPASM100S15.pdf $>$. Acesso em: 22 ago. 2011.

DACHI, S. P. Infecção do trato urinário. Revista Brasileira de Medicina, São Paulo, v. 57, n. 7, p. 759765, jul. 2000.

DIAS NETO, J. A.; MARTINS, A. C. P.; SILVA, L. D. M.; TIRABOSCHI, R. B.; DOMINGOS, A. L. A.; COLOGNA, A. J.; PASCHOALIN, E. L.; TUCCI JUNIOR, S. Community acquired urinary tract infection: etiology and bacterial susceptibility. Acta Cirurgica Brasileira, São Paulo, v. 18, s. 5, p. 33-36, 2003.

DUARTE, G.; MARCOLIN, A. C.; QUINTANA, S. M.; CAVALLI, R. C. Infecção urinária na gravidez. Revista Brasileira de Ginecologia e Obstetrícia, Rio de Janeiro, v. 30, n. 2, p. 93-100, 2008.

DUARTE, G.; MARCOLIN; A. C.; GONÇALVES, C. V.; QUINTANA, S. M.; BEREZOWSKI; A. T.; NOGUEIRA; A. A.; CUNHA, S. P. Infecção urinária na gravidez: análise dos métodos para diagnóstico e do tratamento. Revista Brasileira de Ginecologia e Obstetrícia, Rio de Janeiro, v. 24, n. 7, p. 471-477, ago. 2002.

GUIDONI, E. B. M.; TOPOROVSKI, J. Infecção urinária na adolescência. Jornal de Pediatria, Rio de Janeiro, v. 77, s. 2, p. 165-169, 2001.

HEILBERG, I. P.; SCHOR, N. Abordagem diagnóstica e terapêutica na infecção do trato urinário - ITU. Revista da Associação Médica Brasileira, São Paulo, v. 49, n. 1, p. 109-116, 2003.

JACOCIUNAS, L. V.; PICOLI, S. U. Avaliação de infecção urinária em gestantes no primeiro trimestre de gravidez. Revista Brasileira de Análises Clínicas, Rio de Janeiro, v. 39, n. 1, p. 55-57, 2007.

KOCH, C. R.; RIBEIRO, J. C.; SCHNOR, O. H.; ZIMMERMANN, B. S.; MÜLLER, F. M.; D' AGOSTIN, J.; MACHADO, V.; ZHANG, L. Resistência antimicrobiana dos uropatógenos em pacientes ambulatoriais, 2000-2004. Revista da Sociedade Brasileira de Medicina Tropical, Uberaba, v. 41, n. 3, p. 277-281, maio/jun. 2008.

LABORCLIN. Discos de antibióticos laborclin. Disponível em: <http://www.laborclin.com.br/ produtos/640600/640613_bl.pdf $>$. Acesso em 28 de maio de 2011.

LO, D. S. RAGAZZI, S. L. B.; GILIO, A. E.; MARTINEZ, M. B. Infecção urinária em menores de 15 anos: etiologia e perfil de sensibilidade antimicrobiana em hospital geral de pediatria. Revista Paulistana de Pediatria, São Paulo, v. 28 , n. 4, p. 299-303, 2010.
LOPES, H. V; TAVARES, W. Diagnóstico das infecções do trato urinário. Revista da Associação Médica Brasileira, São Paulo, v. 51, n. 6, p. 306-308, nov./dez. 2005.

LOURA, M. B.; FERNANDES, M. G. A incidência de infecções urinárias causadas por E. coli. Revista Olhar Cientifico, Ariquemes, v. 1, n. 2, p. 411-426, ago./dez. 2010.

MORENO, R. C. Lectura interpretada del antibiograma: ¿ejercicio intelectual o necesidad clínica? Enfermedades Infecciosas y Microbiología Clínica, v. 20, n. 4, p. 176186, 2002.

MOURA, L. B.; FERNANDES, M. G. A incidência de infecções urinárias causadas por E. coli. Revista Olhar Cientifico, Ariquemes, v. 1, n. 2, p. 411-426, ago./dez. 2010.

NASCIMENTO, L. F. C. Epidemiologia de partos prematuros no sudoeste do Brasil: um estudo de base hospitalar. Revista Brasileira de Saúde Materno Infantil, Recife, v. 1, n. 3, p. 263-268, set./dez. 2001.

NEWPROV. Kit para enterobacterias. Disponível em: $\quad<$ http://www.newprov.com.br/uploads/bula/kit enterobacterias.pdf $>$. Acesso em 28 de maio de 2011.

PIRES, M. C. S.; FROTA, K. S.; MARTINS JUNIOR, P. O.; CORREIA, A. F.; CORTEZ-ESCALANTE, J. J.; SILVEIRA, C. A. Prevalência e susceptibilidade bacterianas das infecções comunitárias do trato urinário, em Hospital Universitário de Brasília, no período de 2001 a 2005. Revista da Sociedade Brasileira de Medicina Tropical, Uberaba, v. 40, n. 6, p. 643-647, nov./dez. 2007.

QUEIROZ,P.K.; REIS, C. Suscetibilidade antimicrobiana de Uropatógenos em pacientes ambulatoriais na cidade de Goiânia, GO. Revista da Sociedade Brasileira de Medicina Tropical, Uberaba, v. 38, n. 5, p. 416-420, set./ out. 2005.

SALCEDO, M. M. B. P.; EL BEITUNE, P.; SALIS, M. F.; JIMÉNEZ, M. F.; AYUB, A. C. K. Infecção urinária na gestação. Revista Brasileira de Medicina, São Paulo, v.67, n.8, p.270-273, ago. 2010.

SANTOS, A. C. M.; ZIDKO, A. C. M.; PIGNATARI, A. C. C.; GALES, A. C.; SILVA, R. M. A virulência de Escherichia coli patogênica estra-intestinal (ExPEC) em relação á idade e ao sexo do hospedeiro. $O$ mundo $d a$ saúde, São Paulo, v. 33, n. 4, p. 392-400, 2009.

SATO, A. F.; SVIDZINSKI, A. E.; CONSOLARO, M. E. L.; BÔER, C. G. Nitrito urinário e infecção do trato urinário por cocos gram-positivos. Jornal Brasileiro de Patologia e Medicina Laboratorial, Rio de Janeiro, v. 41, n. 6, p. 397-404, dez. 2005. 
SCHNARR, J.; SMAILL, F. Asymptomatic bacteriuria and symptomatic urinary tract infections in pregnancy. European Journal of Clinical Investigation, Oxford, v. 38, s. 2, p. 50-57, out. 2008.

SILVA, D. Atividade antimicrobiana do Conocarpano seus derivados e análogos frente a cepas resistentes de Staphylococcus aureus. 2007. Dissertação (Mestrado em Ciências Farmacêuticas) - Universidade do Vale do Itajaí, Itajaí.

SILVEIRA, M. G. Atibióticos. Disponível em: < http:// www.hinsg.org.br/pneumologia/aulas/aulas_2007. html>. Acesso em: 24 mar. 2012.

VIEIRA, J. M. S.; SARAIVA, R. M. C.; MENDONÇA, L. C. V.; FERNANDES, V. O.; PINTO, M. R. C.; VIEIRA, A. B. R. Suscetibilidade antimicrobiana de bactérias isoladas de infecções do trato urinário de pacientes atendidos no Hospital Universitário Bettina Ferro de Souza, Belém-PA. Revista Brasileira de Análises Clínicas, Rio de Janeiro, v. 39, n. 2, p. 119-121, 2007. 
